\title{
The changing geography of innovation. Chinese and Indian regions and the global flows of innovation
}

Using an interdisciplinary perspective that combines the geography of innovation studies with international business and innovation studies the thesis contributes to analyze the complementarity role of the region and firm's factors in emerging economies contexts in sustaining firms' innovation performances and their possible modes of participation in the globalization of innovation.

Four different modes of globalization of innovation are taken into consideration: global sourcing of innovation (sources of technology and knowledge from an international organization), global collaboration for innovation (R\&D collaboration with other international organizations), global generation of innovation (offshoring of innovation activities) and global exploitation of innovation (firms' access to international markets through new products and new services).

The empirical focus it is of two specific regions: Pune (India) and Beijing (China) that have undergone very important developments in recent years. The sectors considered are software/ICT, green biotech and automotive components since in all these industries production and innovation activities are already globally distributed. The empirical approach is quantitative and is based on a comparative and econometric analysis of primary data directly collected through two international projects.

The thesis offers important insights to Chinese and Indian firms and policy makers. It shows that to catch up in terms of innovation global interactions are preferable to regional interactions, suggesting the need in these contexts to invest more in their own regional innovation systems.

CIRCLE, Lund University,

Supervisors, Cristina Chaminade, Bjørn T. Asheim.

E-mail: monica.plechero@ circle.lu.se 